\title{
The Significance of Multicomponent Pheromones in Denoting Specific Compositions
}

\author{
ABRAHAM HEFETZ and DAN GRAUR \\ Department of Zoology, George S. Wise Faculty of Life Sciences, Tel Aviv University, Ramat Aviv 69978, Israel
}

Key Word Index-Halictidae; Halictus; Eyylaeus; Lasioghossum; Dufour's gland secretion; macrocyclic lactones; hydrocarbons; species specificity; individual scent; kin recognition.

Abstract-The chemical composition of Dufour's gland secretions of 13 species of halictine bees was investigated. The secretions were composed of a series of macrocyclic lactones, hydrocarbons and isopentenyl esters. The number and relative intensities of these compounds were unevenly distributed among the species, i.e. the secretions were species specific. Based on the empirical data, an algorithm was constructed in order to assess how many of the components present in a secretion are required to discriminate between species, non-related conspecific individuals or nestmates. The results demonstrate that the number of components required for recognition increases with the increase in the level of specificity and with the number of individuals to be identified. The number of compounds denoting identity in a species specific blend may be surprisingly low. Using a similar technique, we assessed the number of components a secretion must contain in order to obtain individual recognition at different levels of relatedness. Several predictions regarding the level of recognition that can be attained by a given pheromone in a given population can be made from these theoretical results.

\section{Introduction}

The information encoded within many pheromones encompasses several levels of communication. For example, in sympatric species a pheromone must not only convey the trivial information that induces a certain behaviour, but must also contain species specific signals. This is well documented in many lepidopteran sex pheromones, for which species specific blends are the basis for reproductive isolation $[1,2]$. In the social insects higher levels of recognition are needed, and indeed are expressed in many pheromones. In Lasius neoniger food trails are nest specific [3], while in Pachicondyla tesserinoda [4] and Leptothorax affinis [5] individual trails are deposited. Individual signals are also used in other contexts. In Lasioglossum zephyrum for instance, males recognize females with which they have recently mated by their individual odours [6]. The ability to discriminate between individuals in Lasioglossum zephyrum or Evylaeus malachurum extends to the recognition of female kin $[7,8]$. Indeed, kin recognition by scent is a hallmark of social insect communication [9]. This ability reaches its peak in

(Received 22 March 1988) the honey bee in which workers are able to distinguish between patrilines in the hive [10, 11]. The various levels of recognition via a pheromonal system obviously require a multicomponent pheromone. The question arises as to how complex should a pheromone blend be in order to denote each level of recognition, and how these numbers are affected by the numbers of individuals (or species) that need to be discriminated. To answer this question we have selected Dufour's gland secretions of halictine bees as a study case.

The function of Dufour's gland in ground dwelling bees is primarily to provide the brood cell with a hydrophobic lining. In some species, such as Eucera palestinae [12] or Evylaeus malachurum [13], the secretion is also used to mark the nest entrance, thus facilitating nest location by the foraging bees. To be effective as a nest marker the secretion should not only be species specific, but should also convey individuality. Indeed, in E. malachurum individualized blends of Dufour's gland were chemically demonstrated [13].

The Halictidae are one of the most investigated groups of bees with respect to Dufour's gland chemistry $[14,15]$. Furthermore, this family 
is outstanding in exhibiting various degrees of sociality [16], a condition that undoubtedly permitted selection for the development of complex social communication systems, in which pheromones probably play a dominant role. Hence, problems of species recognition, as well as individuality, must have been acute during the evolution of this family. These features make the Halictidae an excellent group for testing hypotheses on the mechanisms of recognition via olfactory cues.

\section{Results}

Chemical analysis of the Dufour's gland secretions belonging to the species investigated revealed the presence of at least five groups of compounds; macrocyclic lactones (ranging from $\mathrm{C}_{16}-\mathrm{C}_{26}$ ), paraffins (ranging from $\mathrm{C}_{17}-\mathrm{C}_{27}$ ) and esters, including isopentenyl esters, and methyl and ethyl esters of aliphatic acids. A total of 27 compounds were identified from the various species, albeit not all of them were expressed in each species (Tables 1 and 2). For example, in $E$. marginatum 25 compounds were present in measurable amounts (Fig. 1), while $H$. cochleareitarsis possessed only eight compounds in its Durfour's gland secretion. These results are in accordance with previous chemical analyses of Dufour's gland secretions in this family of bees [13, 17-20].

Based on these empirical data, a computer algorithm was constructed to determine the number of components, within a pheromone consisting of 27 compounds, that are needed to distinguish between two to twelve bees at different levels of relatedness. For each of the 27 components identified in the various species we computed the empirical means and standard deviations of their relative intensities. The variances were partitioned among the following categories: (a) between genera within the family Halictidae, (b) between species within each genus, (c) between nests within the species $E$. malachurum, (d) between random individuals within a nest of $E$. malachurum, and (e) between full-sibs within a nest population. The parti-

TABLE 1. DUFOUR'S GLAND COMPOSITION OF SPECIES IN THE GENUS HAL/CTUS*

\begin{tabular}{|c|c|c|c|c|c|c|}
\hline Species/compound & H. coch. & H. subs. & H. asp. & H. sp. & H. tetr. & V. poll \\
\hline \multicolumn{7}{|l|}{ Heptadecane } \\
\hline \multicolumn{7}{|l|}{ Octadecane } \\
\hline Nonadecane & & & & + & & \\
\hline Methyl palmitate & & + & + & & & \\
\hline \multicolumn{7}{|l|}{ 16-Hexadecanolide } \\
\hline Eicosane & & + & + & & & \\
\hline Heinecosane & ++ & & & + & & \\
\hline Methyl stearate & + & + & ++ & + & & +++ \\
\hline 18-Octadecanolide & & + & $+t+t$ & & $+t+$ & ++ \\
\hline \multicolumn{7}{|l|}{ 18-Octadecenolide } \\
\hline Docosane & + & & + & + & & + \\
\hline Branched lactone +310 & & & & + & & \\
\hline Tricosane & $t+$ & ++ & +++ & +++ & + & ++ \\
\hline 20-Eicosanolide & + & ++++ & $+++t$ & ++ & + & $++t$ \\
\hline 20-Eicosenolide & & ++ & +++ & + & & +++ \\
\hline Tetracosane & & & ++ & + & & \\
\hline Branched lactone +338 & & & & + & & \\
\hline Pentacosane & + & + & + & + & ++ & + \\
\hline 22-Docosanolide & ++++ & +++ & + & ++++ & ++++ & ++++ \\
\hline 22-Docosenolide & + & + & + & + & + & $+t$ \\
\hline Hexacosane & & & + & & & \\
\hline Branched lactone +366 & & & & + & & \\
\hline Heptacosane & & & + & + & & \\
\hline 24-Tetracosanolide & $++t$ & + & + & +++ & $+t+$ & ++ \\
\hline 24-Tetracosenolide & + & & + & + & + & ++ \\
\hline 26-Hexacosanolide & & & & + & & \\
\hline
\end{tabular}

*Abbreviations of the species are as follows: H. coch.-Halictus cochleareitarsis, H. subs. - H. subsenilis, H. asp.-H. asperulus, H. tetr.-H. tetrazoniellus, V. Poll.-Vestitohalictus pollinosus. The relative intensities of the compounds within a blend are expresed as plusses. 
TABLE 2. DUFOUR'S GLAND COMPOSITIONS OF SPECIES IN THE GENERA LASIOGLOSSUM AND EMAEUS*

\begin{tabular}{|c|c|c|c|c|c|c|}
\hline Species/compound & L. aeg. & L. leuc. & E. marg. & E. mor. & E. obs. & E. nig. \\
\hline Heptadecane & & & + & & + & \\
\hline Octadecane & & & + & & & \\
\hline Nonadecane & & & + & & & \\
\hline Methyl palmitate & & & + & & + & + \\
\hline 16-Hexadecanolide & & & & & + & +++ \\
\hline Eicosane & + & & + & & & + \\
\hline Heinecosane & + & & ++ & & + & + \\
\hline Methyl stearate & + & & ++++ & + & + & \\
\hline 18-Octadecanolide & +++ & & +++ & ++++ & ++++ & ++ \\
\hline 18-Octadecenolide & + & ++ & + & + & + & +++ \\
\hline Docosane & + & + & ++ & + & + & + \\
\hline Branched lactone +310 & & & & & + & \\
\hline Tricosane & + & & +++ & + & ++ & ++ \\
\hline 20-Eicosanolide & ++ & & ++++ & ++++ & ++ & + \\
\hline 20-Eicosenolide & + & & ++++ & + & ++ & \\
\hline Tetracosane & + & & ++ & + & + & + \\
\hline Isopentenyl ester & & & & + & + & \\
\hline Branched lactone +338 & & & + & & + & + \\
\hline Pentacosane & + & & ++ & + & + & \\
\hline 22-Docosanolide & + & ++++ & + & ++ & + & \\
\hline 22-Docosenolide & + & + & + & + & & \\
\hline Hexacosane & & & & + & & \\
\hline Branched lactone +366 & & & + & & + & \\
\hline Heptacosane & & & + & + & & \\
\hline 24-Tetracosanolide & & ++ & & & & \\
\hline 24-Tetracosenolide & & ++ & & & & \\
\hline
\end{tabular}

*Abbreviations of the species are as follows: L. aeg.-Lasioglossum aegyptiellum, L. leuc.-L. leucozonium, E. marg.-Evylaeus marginatum, $E$. mor. $-E$. morio, E. abs. $-E$. obscuratum, E. nig. $-E$. nigripes. The relative intensities of the compounds within a blend are expressed as plusses.

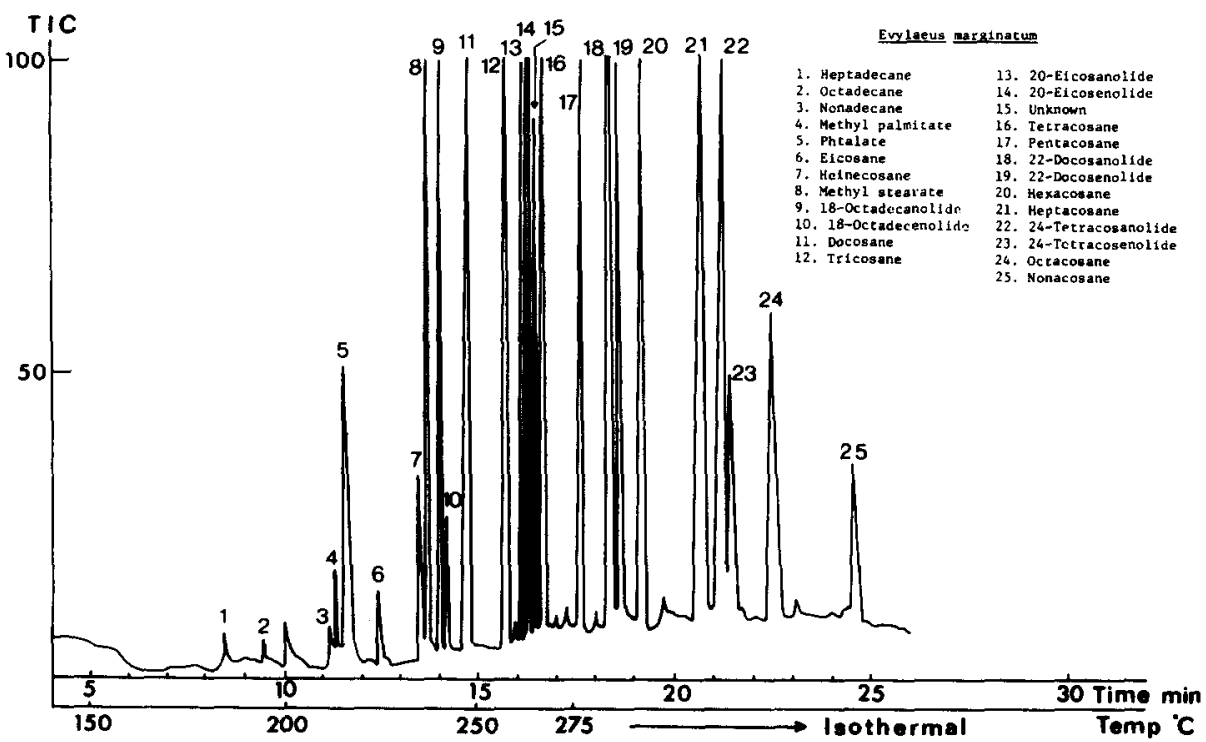

FIG. 1. GAS CHROMATOGRAM OF DUFOUR'S GLAND SECRETION OF E. MARGINATUM. The extract was run on an OV-1 capillary column that was temperature programmed from $150^{\circ}$ to $275^{\circ} \mathrm{min}^{-1}$ at a rate of $10^{\circ} \mathrm{min}^{-1}$ then run isothermally. 
tioning in (a)-(d) was based on the empirical data, whereas the division in (e) was made on the assumption that a population within a nest consists of an equal mixture of full-sibs and halfsibs from an infinite number of fathers. Thus, the results in (e) should be regarded as conservative estimates.

Fifty replicates of 50 'bees' each were generated. Each 'bee' was assigned 27 components in relative quantities determined by the empirical means and standard deviations, and assuming a normal distribution about the mean. Within each 'bee' the various components were then ranked by relative abundance. From each replicate two to twelve 'bees' were chosen at random. For each comparison group we compared the pattern of components in descending order. When the number of components was found to suffice to distinguish between the 'bees' within a sample it was recorded. To illustrate the algorithmic procedure, let us assume that we are comparing two simulated 'bees', A and B. Let us further assume, for simplicity, that their pheromones contain a total of five components (I, II, III, IV and V). By using the means and variances from the empirical data we find that the pheromone of A contains 35\% of component I, $25 \%$ of II, $20 \%$ of III, $15 \%$ of IV and $5 \%$ of V. The simulation for $B$ resulted in $40 \%$ of $\mathrm{I}, 30 \%$ of II, $8 \%$ of III, $20 \%$ of IV and $10 \%$ of V. Thus the order of abundance of components I, II, III, IV and $\mathbf{V}$ in 'bee' $A$ is one, two, three, four and five, respectively, while in 'bee' $B$ the respective ranks are one, two, four, five and three. In this case, we see that three components lout of the five variables) are sufficient to discriminate between the 'bees'. By using only the two most abundant components, we cannot discriminate between $A$ and $B$. In our simulation, for each given number of components and individuals, we recorded the number of times (out of 50 replicates) we were able to discriminate between all individuals in the sample. This proportion is referred as per cent recognition.

The number of compounds out of 27 needed for each level of recognition, and the per cent recognition are presented in Tables 3-5 and Fig. 2. While the number of components in a pheromone blend that will be species specific is obviously dependent on the number of species involved, it is nevertheless rather small. For
TABLE 3. RECOGNITION BETWEEN SPECIES WITHIN THE GENUS HAL/CTUS, BASED ON THE EMPIRICAL DATA OBTAINED FROM ANALYSES OF FIVE SPECIES

\begin{tabular}{|c|c|c|c|c|c|}
\hline $\begin{array}{l}\text { Number of } \\
\text { components }\end{array}$ & $\mathrm{N}^{*}$ & $\begin{array}{c}\% \\
\text { Recognition }\end{array}$ & $\begin{array}{l}\text { Number of } \\
\text { components }\end{array}$ & $\mathrm{N}^{*}$ & $\begin{array}{c}\% \\
\text { Recognition }\end{array}$ \\
\hline $27-29$ & $2-12$ & $98-100$ & 5 & 2 & 100 \\
\hline \multirow[t]{3}{*}{8} & $2-6$ & 100 & & 3 & 96 \\
\hline & $7-8$ & 96 & & 4 & 84 \\
\hline & $9-12$ & 92 & & 5 & 66 \\
\hline \multirow[t]{9}{*}{7} & $2-3$ & 98 & & 6 & 42 \\
\hline & $4-5$ & 92 & & 7 & 16 \\
\hline & 6 & 88 & & 8 & 6 \\
\hline & 7 & 82 & & $9-12$ & 4 \\
\hline & 8 & 76 & 4 & 2 & 78 \\
\hline & 9 & 64 & & 3 & 48 \\
\hline & 10 & 56 & & 4 & 16 \\
\hline & 11 & 52 & & 5 & 8 \\
\hline & 12 & 50 & & 6 & 2 \\
\hline \multirow[t]{11}{*}{6} & 2 & 100 & & $7-12$ & 0 \\
\hline & 3 & 98 & 3 & 2 & 46 \\
\hline & 4 & 96 & & 3 & 8 \\
\hline & 5 & 90 & & $4-12$ & 0 \\
\hline & 6 & 86 & 2 & 2 & 12 \\
\hline & 7 & 66 & & $3-12$ & 0 \\
\hline & 8 & 56 & & & \\
\hline & 9 & 48 & & & \\
\hline & 10 & 40 & & & \\
\hline & 11 & 34 & & & \\
\hline & 12 & 30 & & & \\
\hline
\end{tabular}

${ }^{*} \mathrm{~N}$ denotes the number of bees to be discriminated.

example, discrimination between two sympatric species can be based on only two compounds. Even if there are as many as 12 sympatric species that are using the same set of compounds, five components at most are needed to achieve species specificity (illustrated in Fig. 3). In our simulation we did not investigate the possibility of more than 12 species because of limited computer time. Interestingly, the line for the different genera (Fig. 2), e.g. the number of components needed to discern between two genera, completely overlaps that of the species. The only recognizable biological entity, in this respect, is the species.

When individual badges are important, the number of components necessary for recognition rises slightly. Discrimination between two, unrelated, bees can be accomplished using at least three components. This number increases to six if the number of sympatric species reaches 12 . The really dramatic rise in the need for additional components occurs when the individuals to be distinguished are nestmates. 
TABLE 4. RECOGNITION BETWEEN NESTS WITHIN H. MALACHURUM $\mid$ BASED ON THE EMPIRICAL DATA OBTAINED FROM ANALYSES OF 14 INDIVIDUALS, EACH OF WHICH ORIGINATE FROM A DIFFERENT NEST

\begin{tabular}{|c|c|c|c|c|c|}
\hline $\begin{array}{l}\text { Number of } \\
\text { components }\end{array}$ & $\mathrm{N}^{*}$ & $\begin{array}{c}\% \\
\text { Recognition }\end{array}$ & $\begin{array}{l}\text { Number of } \\
\text { components }\end{array}$ & $\mathbf{N}^{*}$ & $\begin{array}{c}\% \\
\text { Recognition }\end{array}$ \\
\hline $27-10$ & $2-12$ & 100 & 5 & 2 & 94 \\
\hline \multirow[t]{2}{*}{9} & $2-4$ & 100 & & 3 & 86 \\
\hline & 5-12 & 96 & & 4 & 72 \\
\hline \multirow[t]{4}{*}{8} & $2-5$ & 100 & & 5 & 58 \\
\hline & $6-8$ & 94 & & 6 & 52 \\
\hline & 9 & 90 & & 7 & 40 \\
\hline & $10-12$ & 88 & & 8 & 30 \\
\hline \multirow[t]{8}{*}{7} & $2-3$ & 100 & & 9 & 26 \\
\hline & 4 & 98 & & 10 & 20 \\
\hline & 5 & 94 & & $11-12$ & 0 \\
\hline & 6 & 90 & 4 & 2 & 88 \\
\hline & 7 & 86 & & 3 & 76 \\
\hline & 8 & 76 & & 4 & 50 \\
\hline & $9-11$ & 70 & & 5 & 28 \\
\hline & 12 & 8 & & 6 & 24 \\
\hline \multirow[t]{9}{*}{6} & 2 & 100 & & 7 & 12 \\
\hline & $3-4$ & 96 & & 8 & 4 \\
\hline & 5 & 88 & & $9-12$ & 0 \\
\hline & 6 & 80 & 3 & 2 & 60 \\
\hline & 7 & 68 & & 3 & 44 \\
\hline & 8 & 56 & & 4 & 8 \\
\hline & 9 & 54 & & 5-12 & 0 \\
\hline & 10 & 40 & 2 & 2 & 40 \\
\hline & $11-12$ & 34 & & $3-12$ & 0 \\
\hline
\end{tabular}

* $N$ denotes the number of bees to be discriminated.

This is a consequence of the fact that the variation in the composition of the secretions was far greater between individuals from different nests than between nestmates. In the case of nestmates of $E$. malachurum, the minimum number of components necessary to distinguish between two bees is six, and may reach 14 if 12 individuals are involved. This latter number of components is based on the empirical data without assuming any level of genetic relatedness between the nestmates. In the case of $E$. malachurum, all nestmates are daughters of a single mother. Thus, if we assume that a population within a nest consists of an equal number of full- and half-sibs from an infinite number of males, the number of compounds needed for discrimination between sibs is even higher, being 15 for two bees or 17 for 12 bees. Because of the assumption of an infinite number of males, these results should be considered as conservative estimates. In practice, if individualized recognition is required between sibs, and if the paternal lineages are rather
TABLE 5. RECOGNITION WITHIN INDIVIDUALS WITHIN A NEST IN E. MALACHURUM

\begin{tabular}{|c|c|c|c|c|c|}
\hline $\begin{array}{l}\text { Number of } \\
\text { components }\end{array}$ & $\mathrm{N}^{*}$ & $\begin{array}{c}\% \\
\text { Recognition }\end{array}$ & $\begin{array}{l}\text { Number of } \\
\text { components }\end{array}$ & $\mathrm{N}^{*}$ & $\begin{array}{c}\% \\
\text { Recognition }\end{array}$ \\
\hline $19-27$ & 2-12 & 100 & 12 & 6 & 54 \\
\hline 18 & 2-12 & $90-100$ & & $7-12$ & $<50$ \\
\hline \multirow[t]{4}{*}{17} & $2-4$ & 100 & 11 & 2 & 80 \\
\hline & $5-6$ & $80-90$ & & 3 & 72 \\
\hline & 7 & 74 & & 4 & 58 \\
\hline & 8-12 & $60-70$ & & 5-12 & $<50$ \\
\hline \multirow[t]{5}{*}{16} & 2 & 94 & 10 & 2 & 90 \\
\hline & $3-7$ & $80-90$ & & 3 & 88 \\
\hline & 8-9 & 72 & & 4 & 72 \\
\hline & $10-11$ & $60-70$ & & 5 & 56 \\
\hline & 12 & $<50$ & & $6-12$ & $<50$ \\
\hline \multirow[t]{4}{*}{15} & $2-3$ & $90-100$ & 9 & 2 & 94 \\
\hline & $4-5$ & 72 & & 3 & 66 \\
\hline & $6-7$ & $50-60$ & & 4 & 52 \\
\hline & $8-12$ & $<50$ & & 5-12 & $<50$ \\
\hline \multirow[t]{5}{*}{14} & $2-4$ & $90-100$ & 8 & 2 & 90 \\
\hline & 5 & 82 & & $3-4$ & $50-60$ \\
\hline & $6-7$ & $60-70$ & & 5-12 & $<50$ \\
\hline & 8 & 54 & 7 & 2 & 70 \\
\hline & $9-12$ & $<50$ & & $3-12$ & $<50$ \\
\hline \multirow[t]{4}{*}{13} & 2 & 100 & 6 & 2 & 62 \\
\hline & $3-4$ & $80-90$ & & $3-12$ & $<50$ \\
\hline & 5 & 74 & 5 & $2-12$ & $<50$ \\
\hline & $6-12$ & $<50$ & 4 & $2-12$ & $<50$ \\
\hline \multirow[t]{3}{*}{12} & 2 & 100 & 3 & $2-12$ & $<50$ \\
\hline & 3 & 88 & 2 & $2-12$ & $<50$ \\
\hline & 4-5 & $70-80$ & & & \\
\hline
\end{tabular}

* $N$ denotes the number of bees to be discriminated.

limited, the number of components may reach even higher values.

The above-mentioned numbers of components that are sufficient to discriminate between any two given individuals are the minimum numbers; the overall bouquets must evidently be greater. In order to assess how complex the total pheromone bouquet should be, a second algorithm was built. This simulation was concerned with determining the minimum number of constituents within a pheromone that are needed in order to distinguish between 'bees' at a given level of recognition by using either all or a smaller number of the available components. We commenced with the same algorithm as before and proceeded to remove from the initial 27 components one component at each consecutive step of the simulation. The order of component removal was determined by using a list of random numbers. The minimum number of components that still sufficed to distinguish 


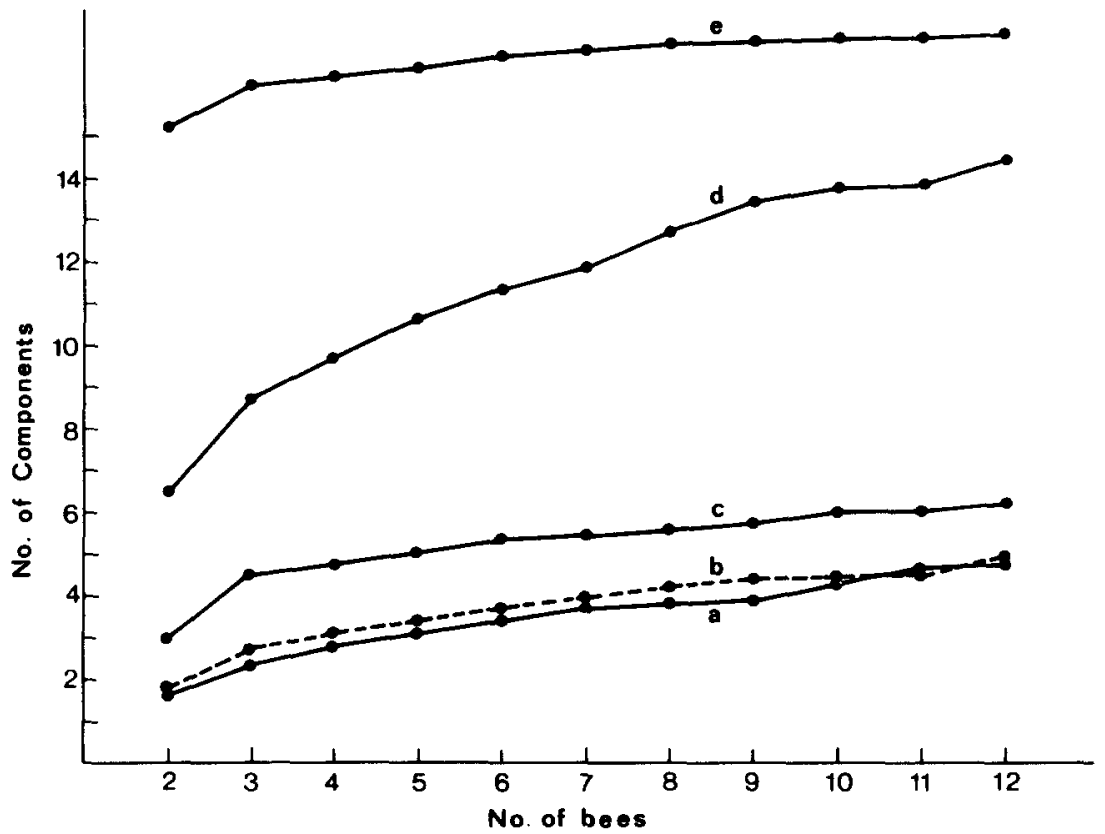

FIG. 2. THE NUMBER OF COMPONENTS OUT OF 27, DETERMINED BY THE COMPUTER ALGORITHM, REQUIRED TO DISCRIMINATE BETWEEN 'BEES'. (a) Of different species. (b) Different genera. (c) Individuals $E$. malachurum from different nests. (d) Nestmates of $E$. malachurum. (e) Full-sibs of E. malachurum. Standard errors were omitted for clarity. All solid lines are significantly different from each other.

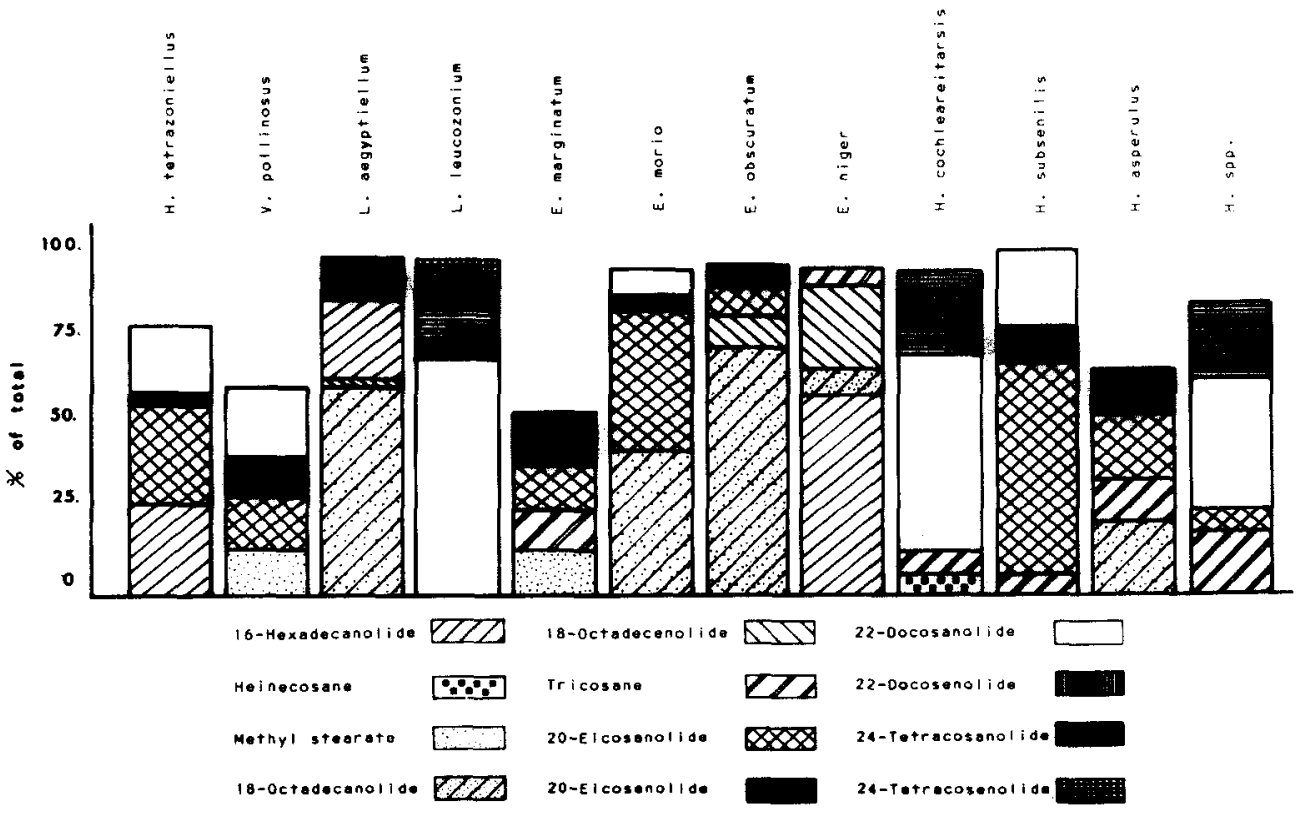

FIG. 3. THE FOUR MOST ABUNDANT COMPONENTS PRESENT IN DUFOUR'S GLAND SECRETION IN EACH OF 12 HALICTINE SPECIES. 
between a given number of individuals was recorded (Fig. 4). As in the first simulation, the minimum number of constituents is affected by the number of individuals involved. At the species level $100 \%$ recognition is reached with five components when two species are involved or nine components when 10 species are involved [Fig. 4(a)]. Thus, when there are 10 sympatric species, species specificity can be imparted by recognition of the four major components (Fig. 2), but the overall number of components in these species must be at least nine [Fig. 4(a)]. Similarly, if an individual odour must be imparted, a blend of six major components is sufficient (for each of the 10 bees involved), but the repertoire of the species should contain at least 19 compounds [Fig. 4(b)].

\section{Discussion}

A message transmitted by semiochemicals cannot be readily altered or modified once it has been sent. It is therefore advantageous to the emitter to include all the information that is to be conveyed by the pheromone within a single blend. This presents not only a problem of how many units of information should be included in the message, but also of how it may be made chemically feasible. One part of the message should obviously include the trivial information that will direct the behavioural changes in the conspecific individual. There should also be a species specific signal so that the perceiving individual will be able to discern it from the multitude of odours that persists in the environment. Often there is a need for a higher degree

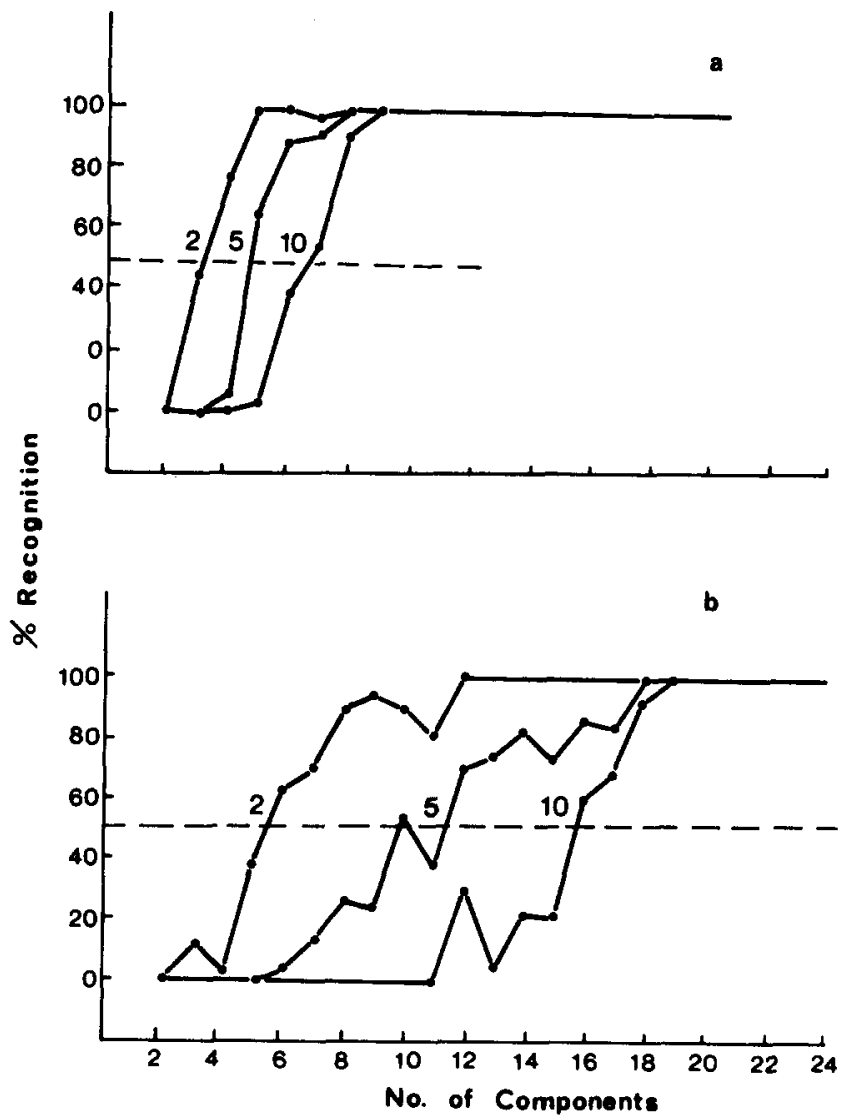

FIG. 4. THE MINIMUM NUMBER OF COMPONENTS IN A BOUQUET THAT ARE REQUIRED FOR DISCRIMINATION BETWEEN (a) SPECies. (b) Conspecific individuals (see text for further details). 
of specificity. This can range from blends characteristic of the population, through kin specific mixture, and up to individual badges. These requirements for specificity are affected largely by the ecology and social structure of the species involved. A single pheromone component may be sufficient to encode the trivial message, but species specificity involving two sympatric species already requires a multicomponent pheromone. Furthermore, when complexes of related species are to be distinguished, the same pheromonal components are probably used, thus depending on the variation of their relative intensities to delineate specificity. This is obviously the case when any higher degree of specificity is mandatory. There are two possible mechanisms, using a multicomponent pheromone, to encode for the various levels of specificity. The animal can consider the whole blend as a unit and compare it to templates that may be present in its brain. In this case it is the higher degree of specificity that is deciphered and all the others become trivial. For example, if kinship is to be recognized by scent, the individual perceiving its mate as kin deduces automatically that this mate is conspecific. A second possibility is that the animals consider the total blend but rank the compounds according to their relative intensities. In this case the recognition of kin is gradual; a few major components denote the species while the variation in all other components may indicate the genetic relatedness of the emitting individual. The empirical data using the pheromones produced by halictine Dufour's gland corroborate the latter modus operandi.

Assuming that the second mechanism prevails, and on the basis of the chemical analyses, several conclusions may be drawn from the computer simulations. The number of compounds in a species specific blend may be surprisingly low, even when several related species living sympatrically are involved. Total discrimination between these species can be achieved with not more than five to nine compounds (Fig. 4). This is indeed the range of components in many of the lepidopteran sex pheromones. The distinction between five conspecific females calling from the same bush, with a recognition error of $50 \%$, demands the presence of at least 10 components in the blend.
Thus, biological processes such as mate selection, that are based on scent alone, are limited by the number of compounds manufactured by the species and the number of individuals involved. If mate selection occurs despite the lower than predicted number of pheromone components, then other cues must participate in the process. If, on the other hand, the pheromone blend includes more compounds than the number predicted for species specificity, then it may be possible that either information of higher levels of specificity is being transmitted, or that some of the components do not take part in the communication process. They may be present in the blend for reasons that are irrelevant to recognition, e.g. excreted metabolites.

Whenever individual odours are important to a dense population, the number of pheromone components must be higher. Indeed, the nest marking pheromone of $E$. palestinae contains at least 22 components [12], and that of $E$. malachurum, 25 components [13]. The latter species is social and the nest marker may also be used in nestmate recognition. Social interactions that are based on scent probably involve the transmission of many units of information. Thus, we should expect an increase in the number of components. In the halictines investigated here the number of components in Dufour's gland secretion varied widely. For instance, in E. leucozonium, a solitary species, the secretion contains six components, while in E. marginatum, a social species, it contains 25 components. Unfortunately there is no information available to date on either the social status of the other species or on whether they use Durfour's gland secretion in a communicative context.

Complete reliance on pheromones for nestmate and kin recognition is possible under two conditions: if the number of components is very high, or if the number of individuals in the nest is rather low. As predicted, many of the exocrine glands of Hymenoptera possess a very large number of components. For example, $C$. ligniperda contains 41 compounds in its Dufour's gland [21] and similarly, the cuticular hydrocarbons that may be used for kin recognition in reticulotermites are numerous [22]. However, if the number of individuals in the nest is very high the system of recognition that is based on individual odours will collapse. There are several 
ways to circumvent this problem. One is to rely on a gestalt odour, where all individuals contribute to the general nest odour. In this case, because of the genetic relatedness between the individuals, their blends are similar and therefore the gestalt approaches each of the individuals in its composition [13]. Another possibility is to introduce an individual cue into an existing signal. This is the case in Camponotus floridanous, where the queen transfers her cues, on the basis of which nestmate discrimination occurs, to the workers [23]. In this case discrimination is effectively based on individual odours. The number of neighbouring nests is limited and even when considering the probability of genetic relatedness between two founder queens, the number of components needed to achieve discrimination may be small. Another means of bypassing the problems of individuality in a large nest is to create subgroups within the nest. In this case a new intermediary level of specificity is introduced with a concomitant reduction in the required number of components, in comparison to the number required for individual recognition. In this way species specificity is not impaired and individuality can also be conveyed. However, there are some genetic limitations to this system, which is probably facilitated by multiple matings of the queen. Such subgroups, for example, may be the basis for patriline distinction in a honey bee hive [11]. It is therefore predicted that in annual colonies containing a small number of nestmates, individual odours may be used. Large colonies, especially in monogamous species, will tend to use the gestalt system or the queen odour to discriminate between nests. In colonies with a medium number of individuals or in those that are polygamous, one should expect the formation of scent groups. This latter possibility is rather intriguing from the evolutionary point of view. Limitations in discriminatory ability based on scent may have led to the formation of subgroups within the nest, and this recognition in turn may have an effect on the social interactions within the colony.

\section{Experimental}

Thirteen species of halictine bees belonging to three genera were analysed in this study (Table 6). The different species
TABLE 6. LIST OF THE SPECIES OF WHICH DUFOUR'S GLAND SECRETION WAS ANALYSED

\begin{tabular}{|c|c|c|c|}
\hline Genus & Subgenus & Group & Species \\
\hline \multirow[t]{6}{*}{ Halictus } & Halictus & Teterazonius & H. spp. \\
\hline & & Teterazonius & H. tetrazoniellus \\
\hline & & Senilis & H. subsenilis \\
\hline & & Sexcinctus & H. cochleareitarsis \\
\hline & & Maculatus & H. asperulus \\
\hline & Vestitohalictus & Mucorous & V. pollinosus \\
\hline \multirow[t]{2}{*}{ Lasioglossum } & Lasioglossum & & L. teucozonium \\
\hline & & & L. aegyptie/lum \\
\hline \multirow[t]{5}{*}{ Lasioglossum } & Evylaeus & & E. morio \\
\hline & & & E. marginatum \\
\hline & & & E. nigripes \\
\hline & & & E. obscuratum \\
\hline & & & E. malachurum \\
\hline
\end{tabular}

were collected on flowers from various places in Israel: Halictus asperulus, $H$. subsenilis, and Vestitohalictus pollinosus from Masua (Jordan Valley); Evylaeus marginatum from $\mathrm{Mt}$ Carmel; Halictus tetrazoniellus from Amazia (Judean Hills), $H$. cochleareitarsis, E. obscuratum, $H$. spp., Lasioglossum leucozonium, L. aegyptiellum and $E$. morio from Maalot (Upper Galilee), and $E$. nigripes from Maagan Michael (coastal plain). Detailed observations on E. malachurum were conducted at a nesting aggregation in Bet-Elazari (coastal plain). Nestmates were collected in a glass vial as they exited from their nest. All bees were chilled on ice while in the field. In the laboratory the bees were dissected under chilled water to remove the Dufour's gland, each of which was placed in a separate vial containing pentane and frozen until further analysis. The carcass of each bee was preserved for identification by $\operatorname{Dr} A$. W. Ebmer from Linz, Austria.

Chemical analyses of the glandular secretions were performed by combined GC and MS using a $50 \mathrm{~m}$ OV-1 capillary column. The eluting compounds were identified by their spectra as compared to spectra published earlier $[17,18]$ and with reference compounds. Quantitative analyses were performed by GC coupled with an integrator, using a $50 \mathrm{~m} \mathrm{SE}$ 30 capillary column. In calculating the relative amounts of the compounds in each of the secretions only those that were measurable by the integrator were considered; the amount of a compound was otherwise valued as zero.

Acknowledgements-We wish to thank Dr A. W. Ember from Linz, Austria for the identification of the bees. Some of the chemical analyses were performed at the Department of Zoology, Oxford University. A. Hefetz wishes to thank Dr M. C. Birch of the Department of Zoology, Oxford University, for his hospitality. D. Graur and A. Hefetz were supported by a grant from the Hertz Foundation and a fellowship from The Royal Society, respectively.

\section{References}

1. Roelofs, W. L. and Carde, R. T. (1974) in Pheromones (Birch, M. C., ed.), pp. 96-114. North Holland, Amsterdam.

2. Roelofs, W. L. and Brown, R. L. (1982) Annu. Rev. Ecol. Sys. 13, 395.

3. Traniello, J. F. A. (1980) Naturwissen. 67, 361. 
4. Jessen, K. and Maschwitz, U. (1985) Naturwissen. 72, 549.

5. Maschwitz, U., Lenz, S. and Buschinger, A. (1986) Experientia 42, 1173.

6. Barrows, E. M. (1975) Behavi Biol, 15, 57.

7. Smith, B. H., Carlson, R. G. and Frazier, J. (1985) Behav' Ecol. Sociobiol. 20, 313.

8. Smith, B. H. and Ayasse, M. (1987) Behav/ Ecol. Sociobiol. 20, 313.

9. Fletcher, D. and Michener, C. D. Kin Recognition in Animals. $465 \mathrm{pp}$. John Willey, New York.

10. Getz, W. M. and Smith, K. B. (1983) Nature 302, 147.

11. Gez, W. M., Bruckner, D. and Smith, K. B. (1986) J. Comp. Physiol. A 159, 251.

12. Shimron, O., Hefetz, A. and Tengo, J. (1985) Insect Biochem. 15, 635.

13. Hefetz, A., Bergstrom, G. and Tengo, J. (1986) J. Chem. Ecol. 12, 197.

14. Duffield, R. M., Wheeler, J. W. and Eickwort, G. C. (1984) in Chemical Ecology of insects (Bell, W. J. and Cared, R. T., eds), pp. 387-428. Chapman and Hall, London.
15. Hefetz, A. (1987) Physiol. Entomol. 12, 243.

16. Michener, C. D. (1974) The Social Behavior of the Bees. A Comparative Study, 404 pp. Harvard University Press, Cambridge, MS.

17. Hefetz, A., Blum, M. S., Eickwort, G. C. and Wheeler, J. W. (1978) Comp. Biochem. Physiol. 61B, 129.

18. Duffield, R. M., Fernandes, A., Lamb, C., Wheeler, J. W. and Eickwort, G. C. (1981) J. Chem. Ecol. 7, 319.

19. Andersson, C. O., Bergstrom, G., Kullenberg, B. and Stallberg-Stenhagen, S. (1966) Arkiv Kemi Band 26, 191.

20. Johansson, I., Svensson, B. G., Tengo, J. and Bergstrom, G. (1982) insect Biochem. 12, 161.

21. Bergstrom, G. (1972) in Chemical Releasers in Insects (Tahori, A. S., ed.), pp. 195-223. Gordon and Breach, New York.

22. Howard, R. W., McDaniel, C. A., Neison, D. R., Blomquist, G. J., Gelbaum, L. T. and Zlkow, L. H. (1982) J. Chem. Ecol. 8, 1227.

23. Carlin, N. F. and Holldobler, B. (1986) Behavl. Ecol. Sociobiol. 19, 123. 